\title{
Reduction of Plastic Deformation in Heavy Traffic Intersections in Urban Areas
}

\author{
Seungbub Song and Chunho Yeom *(1)
}

International School of Urban Sciences, University of Seoul, Seoul 02504, Korea; seungbub@nate.com

* Correspondence: chunhoy7@uos.ac.kr; Tel.: +82-2-6490-5154

\begin{abstract}
This study aims to maximize the effects of reducing plastic deformation in heavy traffic intersections in urban areas by improving the aggregates and binders of asphalt mixtures in order to verify the strength effect of SMA (Stone Mastic Asphalt) mixtures compared with that of fluidresistant asphalt mixtures. The authors examine the pavement performance and conduct an economic analysis for sustainable urban infrastructure. Additionally, to reduce plastic deformation, the study analyzed an improvement plan through experimental research based on the existing literature. First, we determined the mixing design specifications of the general asphalt fluid-resistant mixture and SMA mixture, which is known to reduce plastic deformation. Next, we confirmed the appropriateness of the raw materials and mixing design results. Finally, a performance test was conducted on plastic deformation resistance. A wheel tracking test was also conducted as a performance experiment. The test body—with a fiber grid reinforcing material installed in the SMA mixture-showed high dynamic stability, which was the most effective for reducing plastic deformation.
\end{abstract}

Keywords: plastic deformation; pavement performance; wheel tracking test; sustainable infrastructure; SMA

check for

updates

Citation: Song, S.; Yeom, C. Reduction of Plastic Deformation in Heavy Traffic Intersections in Urban Areas. Sustainability 2021, 13, 4002. https://doi.org/10.3390/su13074002

Academic Editor: Ali Jamshidi

Received: 2 March 2021

Accepted: 1 April 2021

Published: 3 April 2021

Publisher's Note: MDPI stays neutral with regard to jurisdictional claims in published maps and institutional affiliations.

Copyright: (C) 2021 by the authors. Licensee MDPI, Basel, Switzerland. This article is an open access article distributed under the terms and conditions of the Creative Commons Attribution (CC BY) license (https:/ / creativecommons.org/licenses/by/ $4.0 /)$.

\section{Introduction}

Plastic deformation of asphalt pavements in metropolitan areas hinders smooth passage for road users [1,2] and adds to the social costs of road maintenance [3,4]. In summer, metropolitan intersections are particularly vulnerable to plastic deformation because of the behavior of asphalt mixtures at high temperatures. This is mostly the effect of heavy vehicle traffic and long waiting periods [5-8]. Unlike normal cases where road surfaces-such as auxiliary layers, substrates, intermediate layers, and surface layers-connect, traffic cannot be completely switched in these intersections. Therefore, in most cases of pavement damage, surface cutting and overlaying methods are applied. However, it is becoming challenging to secure the long-term commonality of the pavement due to the lack of shear strength relative to the traffic load compared with the shear surface pavement. Figure 1 shows a typical case of plastic deformation on asphalt pavement in the metropolitan intersection.

In this study, the authors analyzed methods to decrease plastic deformation in metropolitan intersections through experimental research based on prior research results. First, the authors determined the specifications of combining the general asphalt fluidresistant mixture and SMA (Stone Mastic Asphalt) mixture, which effectively reduces plastic deformation. SMA consists of three major components, aggregates, asphalt, and fiber. It has a relatively high portion of coarse aggregates and asphalt compared to conventional asphalt concrete to retain a certain level of resistance to a crack. At this time, the component of fiber works to prevent bleeding and rundown of asphalt [9-12]. In addition, performance experiments using a wheel tracking test were conducted to examine the plastic deformation resistance. These experiments analyzed road pavement conditions consequential to plastic deformation caused by actual vehicle load. The authors also compared the test specimen with a glass fiber grid-reinforced SMA mixture to maximize plastic deformation resistance. An indoor wheel tracking experiment was conducted to analyze the road pavement in the closest condition to plastic deformation due to actual vehicle 
load. Additionally, a test piece equipped with an SMA mixture reinforced with a glass fiber grid to maximize resistance against plastic deformation was compared.

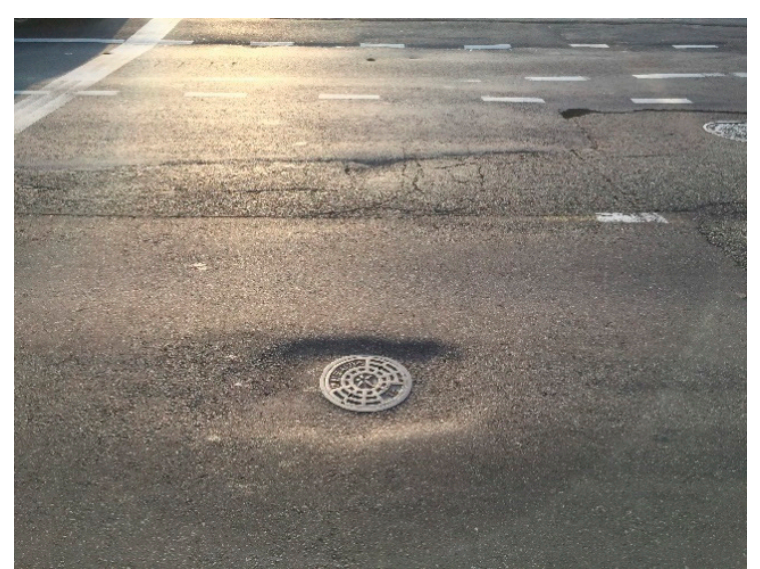

(a)

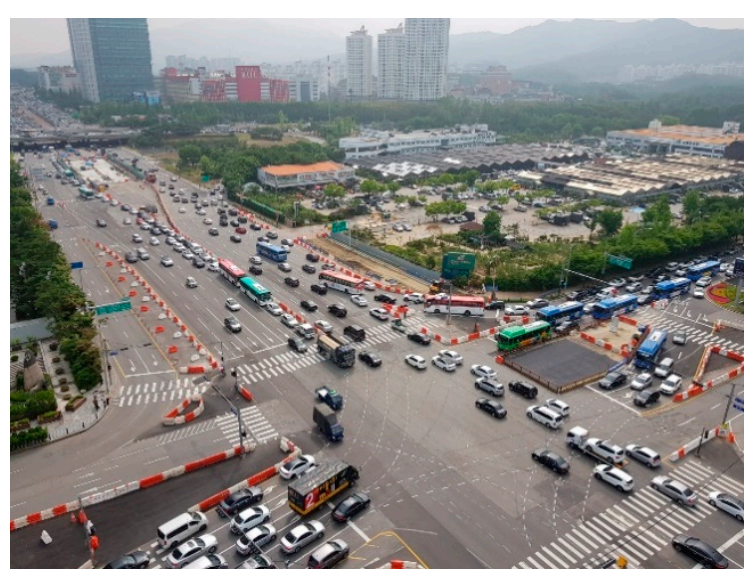

(b)

Figure 1. (a) Plastic Deformation; (b) Metropolitan Intersection (Yeomgok Crossing).

Previous studies mostly analyzed theoretical interpretations and engineering improvements. However, this study utilized the results of wheel tracking experiments and analyzed the commonality of road pavement and economic factors for providing an appropriate practical measure. Furthermore, the study can help reduce future social costs due to poor pavement, such as plastic deformation, by suggesting improvements in related laws and systems, such as design, construction, and supervision.

\section{Consideration of Prior Research}

\subsection{Prediction of Plastic Deformation}

Choi et al. selected $10 \mathrm{~cm}$ of surface layer, $20 \mathrm{~cm}$ of the base layer, and $30 \mathrm{~cm}$ of auxiliary base as representative sections of the two intersections with the highest traffic volume within the Daejeon Land Management Agency. They applied dynamic modulus parameters for each section [13]. Next, using the two-dimensional axial finite element method, it was interpreted. The results were substituted in the commonality model to predict plastic deformation of $13 \mathrm{~mm}$ PG 64-22 with general asphalt density and $13 \mathrm{~mm}$ PG 76-22 with polymer modified asphalt density. However, plastic deformation of fiberreinforced asphalt pavement could not be predicted using the parameters presented in the Korean pavement design method. Therefore, the dynamic stability values obtained from wheel tracking experiments of numerous prior studies were applied to measure the dynamic stability of the modified asphalt's test specimen. The authors then predicted the plastic deformation of fiber-reinforced asphalt by measuring its dynamic stability and substituting the ratio to the estimated plastic deformation of polymer modified asphalt interpreted with the two-dimensional axial symmetry finite element method. Regression analysis measured the changes in public life for plastic deformation by pavement method according to the traffic volume. The results showed that all three pavement methods of up to 1200 units of converted axial load traffic were satisfactory, assuming a 10-year design life of the recommended plastic deformation in a $15 \mathrm{~mm}$ standard pavement. However, if the conversion exceeded 1200 units, the public service period of the general seal asphalt pavement method did not exceed ten years. If the traffic exceeded 1800 or more, the polymer modified asphalt pavement method did not meet the design life. Additionally, the fiber-reinforced asphalt pavement did not satisfy the public service period of 10 years when the conversion load exceeded 2000 units. In the case of 2000 units of converted axial load traffic, the service period of the fiber-reinforced asphalt was 2.01 times longer than the general density pavement method and 1.55 times longer than the improved asphalt pavement method. 
Viscoelastic property of asphalt on permanent deformation was also studied by numerous researchers $[9,14,15]$. Ling et al. (2017) were focused on oxidative aging, while $\mathrm{Xu}$ and Solaimanian (2009) and Kim and Little (2004) were focused on modeling linear viscoelastic property. Since dynamic modulus is one of the most important properties in the permanent deformation of asphalt pavement, it is critical to understand the aging characteristics considering temperatures.

\subsection{Study of General Combinations}

Ko suggested a guideline for preventing plastic deformation divided into four classes [16]. This was possible by separating the internal and external causes of plastic deformation. In the case of internal plastic deformation, selection test methods of aggregate-which accounts for $90 \%$ of the mixture-were improved, and a scientific rating system for asphalt binders was introduced. Regarding the external causes, the author conducted a repeat creep test of the mixture, wheel tracking test, binder performance rating test of SHRP, and the conventional Marshall stability test. Super-19 mixtures (19 mm density, less than 5\% colon stone, PG 64-22) improved the properties of aggregates in packages with a high probability of plastic deformation, and the dynamic stability test results showed $6416 / \mathrm{mm}$ and WC-3 mixture 915 times. Furthermore, since the Marshall stability test is independent of asphalt plastic deformation resistance and mechanical properties, new test methods and design criteria are needed to test the commonality of pavement.

Ock et al. analyzed the elevation specifications of the existing millipede asphalt mixture through the wheel tracking test. They proposed the introduction of a flow resistance elevation, set slightly off the bottom of the Superpave hazard area, to resolve elevation-related issues [17].

Kim et al. studied the method of defining asphalt mixtures as a compound material functioning by interacting with asphalt binders and maximizing contact between aggregates without improving the performance of the asphalt binder. They concluded that this method was limited in increasing the plastic resistance of asphalt mixtures [18], implying that the conjugate material is necessary to constrain the aggregates from shear flow under dynamic vertical loads.

Wheel tracking tests and tensile fatigue tests were conducted using two types of polymers, LDPE and SBS, which proved their performance in Korea. The tests showed a decreased rate of plastic deformation of about $27 \%$ and $64 \%$ in LDPE and SBS reforming materials, respectively, compared with normal mixtures. In addition, the vertical creep growth rate was checked through a tensile fatigue test, and LDPE reforming materials showed a decrease of about $50 \%$ and SBS by about $45 \%$ compared with normal composites. The Marshall stability value-which represents the strength characteristics of asphalt mixtures-also shows little difference in the mixtures with polymer-based modifying materials compared with basic mixtures. Therefore, the conventional Marshall stability test is insufficient in determining plastic deformation resistance.

\subsection{Civil Fiber Reinforcement Mixture Study}

Through numerous studies on the pavement methods of fiber-reinforced asphalt, Yeo et al. determined that fiber-reinforced asphalt is excellent in preventing fatigue cracks and reflective cracks and resisting plastic deformation [19]. The researchers selected fiberreinforced asphalt pavement trial construction sections and comparative sections (general or modified asphalt pavement). Automatic survey equipment was used to record data about crack rates, rutting, IRI, and sagging in $10 \mathrm{~m}$ intervals. The data were examined through statistical methods, and it was then compared and analyzed. Based on the $90 \%$ probability of rutting, the fiber-reinforced trial construction section of the Sindoan bridge was reduced by about $70 \%$ compared with the normal asphalt pavement section. Additionally, the fiber-reinforced trial section of the Haguduk crossway was reduced by about $19 \%$ compared with the modified asphalt pavement section. 
To compare the reinforcement effects of civil fiber-reinforced asphalt pavement, Cho and Lee conducted a commonality evaluation by selecting six sections, including general asphalt, modified asphalt, and civil fiber-reinforced asphalt [20]. Plastic deformation occurred from $2.87 \mathrm{~mm}$ to $4.45 \mathrm{~mm}$ after 85 months of public use. Unlike general expectations, sections that used glass fiber composites showed relatively high rates of plastic deformation. Thus, using modified asphalt or civil fiber-reinforcement did not restrain plastic deformation. This can be attributed to insufficient construction management of asphalt materials due to winter construction and reduced adhesion of civil fiber-reinforcement. In the case of crack rates, glass fiber sheets showed an improvement of about 1.5 to 4.0 times, whereas glass fiber composite fabric showed an improvement of about 2.75 to 13 times.

\subsection{Summary of Previous Research}

Two main countermeasures for reducing plastic deformation were presented in prior research. First, the researchers presented improvements for aggregates, which account for at least $90 \%$ of the total volume of asphalt mixtures [16]. Second, to predict resistance against plastic deformation, the researchers evaluated a field survey about plastic deformation rates considering several actual traffic loads under mixed entry conditions of various specifications and dynamic stability values obtained from indoor wheel tracking tests $[20,21]$. However, the results of each field survey and wheel tracking test did not reflect the exact entry of mixtures, aggregate grades, and binder grades; the results reflected $13 \mathrm{~mm}$ of the dense mixture, $13 \mathrm{~mm}$ of modified asphalt dense mixture, $19 \mathrm{~mm}$ of WC-3, and $25 \mathrm{~mm}$ of the large stone mixture. The detailed study by Ko on the factors of asphalt pavement plastic deformation was conducted 19 years ago, and large stone mixture $(25 \mathrm{~mm})$ surfaces and $19 \mathrm{~mm}$ SMA were used, which are rarely used now. Given the above, Ko's study lacks practicality [10].

In contrast, the present study reflects the latest construction trends. We conducted an indoor test by applying $19 \mathrm{~mm}$ density analysis and $13 \mathrm{~mm}$ density SMA. Different binder classes of the same densities were also applied, and the wheel tracking test results were analyzed on the basis of different samples of 1st-class aggregates (SMA) and 2nd-class aggregates (WC-5). To plan and implement construction projects, the cost of maximizing financial gains should be determined using limited resources for analyzing the necessary feasibility studies. To achieve this, it is essential to ensure the efficiency of economic investment costs. However, almost all prior research results considered only the engineering and technical aspects. Thus, there is a lack of research that suggests economic and efficient measures. In contrast, this study aims to implement commonality and economic feasibility evaluations to verify the effectiveness of asphalt mixtures differently applied during wheel tracking test analysis. This is done to provide the minimum range for project managers to select appropriate asphalt mixtures according to different field conditions.

\section{Research Methods and Analysis}

\subsection{Research Methods}

The study aimed to pursue the active reduction of plastic deformation constrained within the spatial scope of intersections in urban areas with more traffic than regular roads. After Superpave, a new concept asphalt mixture design system designed in the U.S., proved effective, issues such as pavement damage due to the rapid increase in traffic volume on asphalt pavements in Korea arose. The Superpave method may not be in line with the field conditions in Korean infrastructure, thereby raising concerns about its direct implementation. Consequently, in the late 1990s, research was initiated on securing longterm commonality of pavements, such as studies on pavement methods suitable for Korea. The authors analyzed 20 years of prior research aimed at decreasing plastic deformation to increase the long-term commonality of pavement.

Based on existing research, the authors determined the ratio of the fluid resistance mixture - an effective measure against plastic deformation — and the crushed stone mastic SMA. The modified asphalt binders with a commonality grade of PG76-22 were applied to 
the dynamic stability value of the SMA formulation. Next, the results were analyzed. The process flowchart for this study is shown in Figure 2.

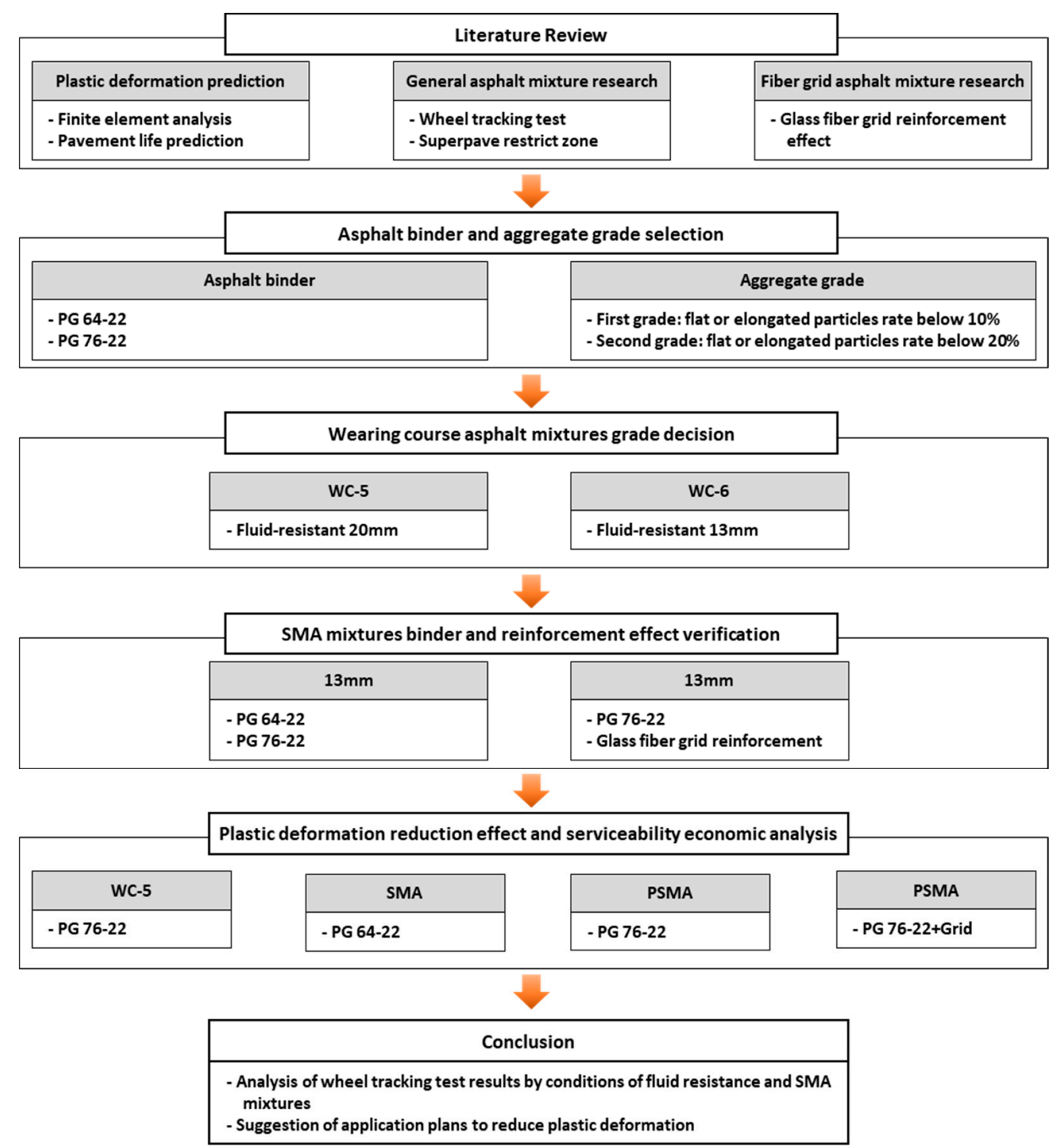

Figure 2. Study Flow.

\subsection{Analysis of Fluid-Resistant Mixture Design}

A fluid-resistant combination design — with high resistance against plastic deformationshould satisfy the conditions of an S-Curve design. S-Curve design slightly avoids the Superpave restriction zone by going under it. The larger the maximum size of the coarse aggregate, the higher the resistance against plastic deformation. Therefore, in this study, WC -5 combinations with a maximum aggregate size of $20 \mathrm{~mm}$ were applied instead of $13 \mathrm{~mm}$ WC- 6 combinations. Consequently, the conditions were more favorable for resisting plastic deformation. Hot bin synthetic gradation of the composite was below the Superpave restriction zone and satisfied the specification coverage, as shown in Table 1 and Figure 3. 
Table 1. Second-class aggregates (WC-5) hot bin synthetic gradation.

\begin{tabular}{cccccccccc}
\hline Size & $\mathbf{2 0} \mathbf{~ m m}$ & $\mathbf{1 3} \mathbf{~} \mathbf{m}$ & $\mathbf{1 0} \mathbf{~} \mathbf{m}$ & $\mathbf{5} \mathbf{~ m m}$ & $\mathbf{2 . 5} \mathbf{~ m m}$ & $\mathbf{0 . 6} \mathbf{~ m m}$ & $\mathbf{0 . 3} \mathbf{~ m m}$ & $\mathbf{0 . 1 5} \mathbf{~ m m}$ & $\mathbf{0 . 0 8} \mathbf{~} \mathbf{m}$ \\
\hline Synthetic gradation (\%) & 100 & 79.3 & 60.7 & 42.7 & 32.5 & 16.3 & 11.9 & 9.0 & 6.0 \\
Center gradation (\%) & 95 & 76.5 & 65 & 45 & 30.5 & 16.5 & 10.5 & 7.5 & 6.0 \\
Standard (\%) & $90 \sim 100$ & $69 \sim 84$ & $56 \sim 74$ & $35 \sim 55$ & $23 \sim 38$ & $10 \sim 23$ & $5 \sim 16$ & $3 \sim 12$ & $2 \sim 10$ \\
Restrict Zone (\%) & & & & & 34.6 & $16.7 \sim 20.7$ & 13.7 & & \\
\hline
\end{tabular}

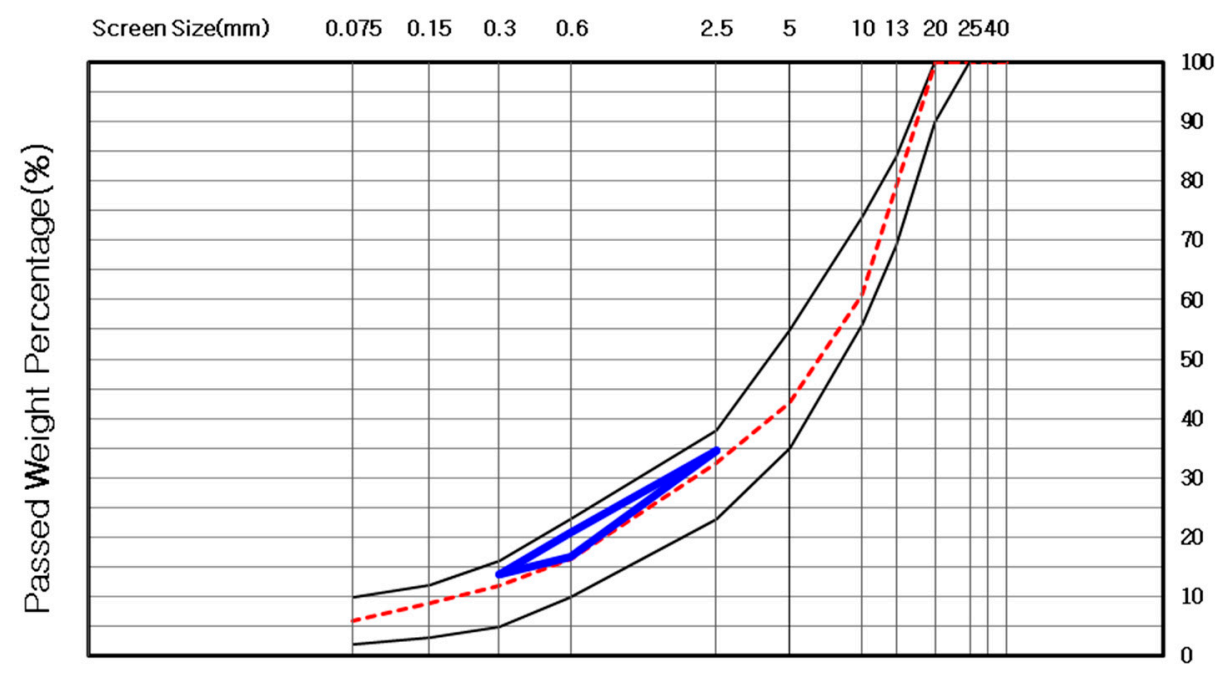

Figure 3. WC-5 Synthetic Gradation Graph.

Tables 2 and 3 show the cold bin mix ratio of the fluid-resistant WC- 5 mixture design and the final hot bin mix ratio. Aggregates accounted for about $92 \%$ of the total volume, whereas coarse aggregates accounted for about $53 \%$. When designing combinations, WC-5 $13 \mathrm{~mm}$ aggregates were determined and applied as second-grade aggregates. However, by analyzing the usage rate of cold bin aggregates, the usage rate of first-grade $20 \mathrm{~mm}$ aggregates (elongation $7 \%$ ) was higher than that of second-grade $13 \mathrm{~mm}$ aggregates (elongation $13 \%$ ). The general usage rate of elongated particles was less than $10 \%$ at $8.9 \%$, thereby making it a first-grade aggregate.

Table 2. WC-5 cold bin mix ratio.

\begin{tabular}{ccccc}
\hline Section & $\begin{array}{c}\text { Aggregate Mix Ratio } \\
(\mathbf{\%})\end{array}$ & $\begin{array}{c}\text { Mixture Ratio } \\
\mathbf{( \% )}\end{array}$ & $\begin{array}{c}\text { Mix Amount } \\
(\mathbf{k g})\end{array}$ & Note \\
\hline PG 76-22 & $\mathrm{n} / \mathrm{a}$ & 5.2 & 52.0 & $\mathrm{n} / \mathrm{a}$ \\
$20 \mathrm{~mm}$ & 39.0 & 37.0 & 369.7 & 1 Grade \\
13 mm & 18.0 & 17.1 & 170.6 & 2 Grade \\
Fine Aggregate & 40.0 & 37.9 & 379.2 & $\mathrm{n} / \mathrm{a}$ \\
Fill Material & 3.0 & 2.8 & 28.4 & $\mathrm{n} / \mathrm{a}$ \\
Total & 100.0 & 100.0 & 1000.0 & 1 Grade \\
\hline
\end{tabular}

Table 3. Final WC-5 hot bin mix ratio.

\begin{tabular}{ccc}
\hline Section & Mixture Ratio (\%) & Mix Amount (kg) \\
\hline PG 76-22 & 5.2 & 52.0 \\
3BIN (20 13 mm) & 20.9 & 208.6 \\
2BIN (13 5 mm) & 32.2 & 322.3 \\
1BIN (5 mm below) & 38.9 & 388.7 \\
Fill Material & 2.8 & 28.4 \\
Total & 100.0 & 1000.0 \\
\hline
\end{tabular}




\subsection{Analysis of SMA Mixture Design}

Currently, the crushed stone mastic SMA mixture is widely accepted as the optimal method against plastic deformation. This mixture has a distinctly different range of granularity compared with normal density or fluid-resistant combination designs, as shown in Table 4 and Figure 4. Additionally, the proportion of coarse aggregate is significantly higher than that of general density combination designs. Furthermore, within the scope of the specifications reflecting these characteristics, the particle size of the SMA mixtures used in the study was appropriately determined.

Table 4. Samples of 1st-class aggregates (SMA) hot bin synthetic gradation.

\begin{tabular}{|c|c|c|c|c|c|c|c|c|c|}
\hline Size & $20 \mathrm{~mm}$ & $13 \mathrm{~mm}$ & $10 \mathrm{~mm}$ & $5 \mathrm{~mm}$ & $2.5 \mathrm{~mm}$ & $0.6 \mathrm{~mm}$ & $0.3 \mathrm{~mm}$ & $0.15 \mathrm{~mm}$ & $0.08 \mathrm{~mm}$ \\
\hline Synthetic gradation (\%) & 100 & 99.2 & 50.5 & 26.0 & 19.7 & 14.4 & 12.8 & 11.2 & 9.4 \\
\hline Center gradation (\%) & 100 & 96.5 & 47.5 & 23.0 & 17.5 & 14.0 & 11.5 & 10.5 & 9.5 \\
\hline Standard (\%) & 100 & $93 \sim 100$ & $40 \sim 55$ & $16 \sim 30$ & $12 \sim 23$ & $10 \sim 18$ & $8 \sim 15$ & $7 \sim 14$ & $7 \sim 12$ \\
\hline Restrict Zone (\%) & & & & & 34.6 & $16.7 \sim 20.7$ & 13.7 & & \\
\hline
\end{tabular}

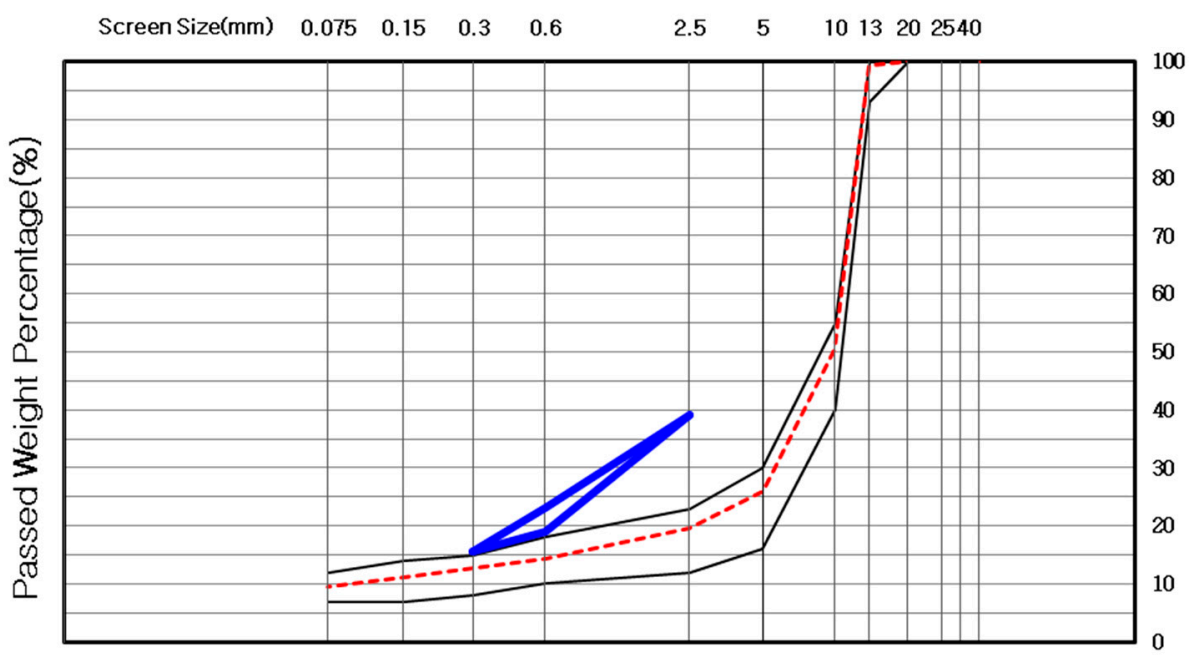

Figure 4. SMA Synthetic Gradation Graph.

As shown in Table 5, SMA mixtures require 30\% more coarse aggregates than regular asphalt mixtures. To bind the relatively large amounts of aggregates, $20 \%$ more asphalt binders are required. The increased usage of asphalt binders implies that separate cellulose fibers should be implemented to prevent large amounts of asphalt binders from flowing down.

Table 5. SMA cold bin mix ratio.

\begin{tabular}{ccccc}
\hline Section & $\begin{array}{c}\text { Aggregate Mix Ratio } \\
(\mathbf{\%})\end{array}$ & $\begin{array}{c}\text { Mixture Ratio } \\
\mathbf{( \% )}\end{array}$ & $\begin{array}{c}\text { Mix Amount } \\
(\mathbf{k g})\end{array}$ & Note \\
\hline PG 76-22 & $\mathrm{n} / \mathrm{a}$ & 6.4 & 64.0 & \\
$13 \mathrm{~mm}$ & 64.0 & 59.6 & 596.5 & 1 Grade \\
$10 \mathrm{~mm}$ & 12.0 & 11.2 & 111.8 & 1 Grade \\
Fine Aggregate & 15.0 & 14.0 & 139.8 & $\mathrm{n} / \mathrm{a}$ \\
Fill Material & 9.0 & 8.4 & 83.9 & $\mathrm{n} / \mathrm{a}$ \\
Cellulose Fiber & $\mathrm{n} / \mathrm{a}$ & 0.4 & 4 & $\mathrm{n} / \mathrm{a}$ \\
Total & 100.0 & 100.0 & 1000.0 & 1 Grade \\
\hline
\end{tabular}

The hot bin composite ratio of the SMA mixture, as shown in Table 6, was examined. The results showed that aggregates account for about $85 \%$ of the total volume, while coarse aggregates account for about $69 \%$. About 1.3 times more aggregates were used compared to 
the fluid-resistant mixture. Therefore, the properties of crushed stone mastic mixtures allow for a tight contact and engagement of aggregates and effectively resist plastic deformation from compressive and shear forces caused by traffic loads.

Table 6. Final SMA hot bin mix ratio.

\begin{tabular}{ccc}
\hline Section & Mixture Ratio (\%) & Mix Amount (kg) \\
\hline PG 76-22 & 6.4 & 64.0 \\
3BIN (13 5 mm) & 15.8 & 158.4 \\
2BIN (10 2.5 mm) & 53.1 & 531.2 \\
1BIN (5 mm Below) & 15.8 & 158.4 \\
Fill Material & 8.4 & 83.9 \\
Cellulose Fiber & 0.4 & 4.0 \\
Total & 100.0 & 1000.0 \\
\hline
\end{tabular}

\subsection{Analysis of Wheel Tracking Test}

Wheel tracking tests are among the most reliable verification methods for enhancing the resistance of plastic deformation in asphalt mixtures. Under hot summer temperature conditions $\left(60^{\circ} \mathrm{C}\right)$, traffic loads are repeatedly and directly transferred to the test specimen to calculate dynamic stability values by the number of wheel passes required for a depressed depth of $1 \mathrm{~mm}$. PG 64-22 and 76-22 of the fluid-resistant WC-5 mixture were differently applied to the test specimens. The SMA mixture was tested with the differential application of asphalt binders; additional fiber grid reinforcements were also applied and experimented with.

As shown in Figure 5, a test specimen was applied to the PG 76-22 modified asphalt binders of the SMA mixture and the fiber grid reinforcement. The results showed a dynamic stability rate of 5339 times per $\mathrm{mm}$. Similarly, it showed approximately 1.33 times better results than the SMA mixture specimens in cases where fiber grid reinforcements were not applied. A 2.6 times higher dynamic stability rate than fluid-resistant asphalt mixture PG 64-22 and a 1.5 times higher rate than PG 76-22 were also revealed. This may be the result of the fiber reinforcement controlling the kinetic energy of aggregates in the asphalt mixture against the test load and minimizing the deformation.

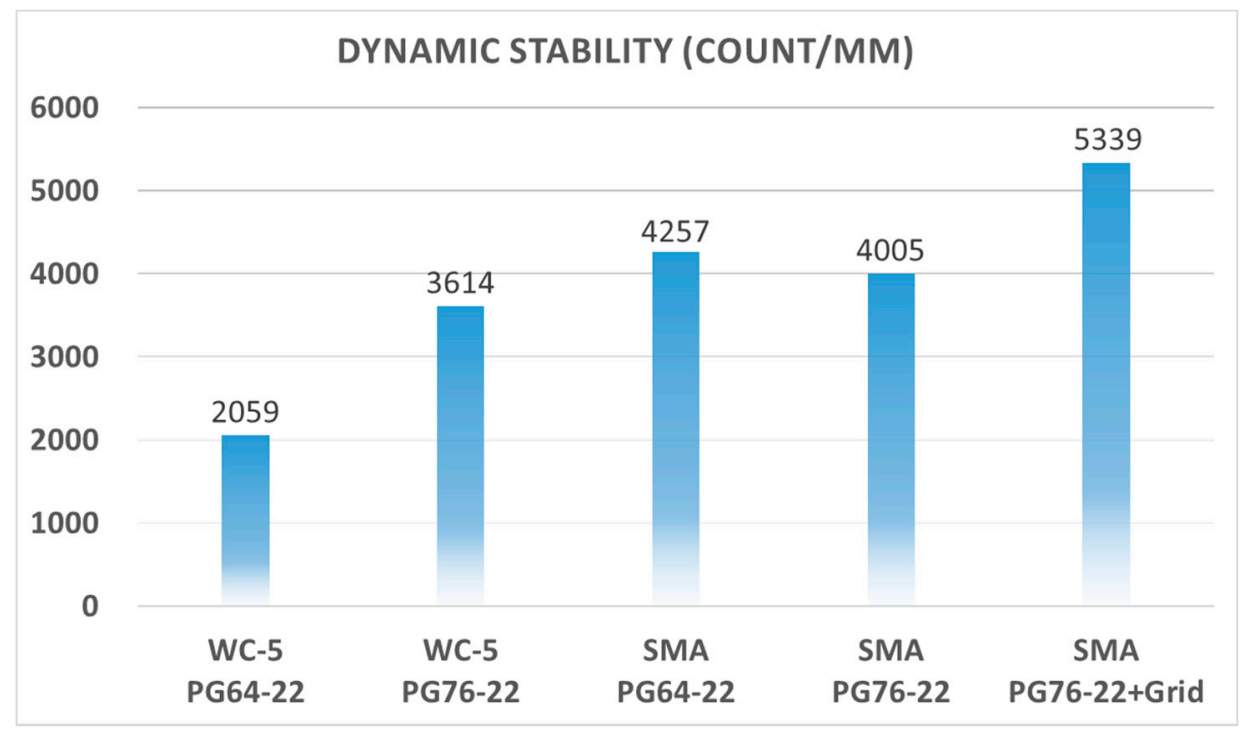

Figure 5. Comparison of Wheel Tracking Test Results.

However, an SMA mixture design with only first-grade aggregates was applied. According to the results, using the PG 64-22 regular straight asphalt binders showed a 
6.3\% higher dynamic stability value than using PG 76-22 modified asphalt binders. Under summer high-temperature conditions, because of the properties of plastic deformation, the interlocking aggregates of SMA mixtures are primarily involved in the resistance of plastic deformation when the asphalt goes through viscous movements. Consequently, the effect of asphalt binders decreases, and the effect of interlocking first-grade aggregates on plastic deformation increases.

\section{Application of Performance and Economic Analysis}

\subsection{Performance Analysis}

The Ministry of Land, Infrastructure, and Transport's Korea Pavement Research Program was used for analyzing the experiment's results [21]. Material properties of $20 \mathrm{~mm}$ were applied to the WC-5 standard based on 100,000 units of daily traffic between mid-city traffic intersections - the spatial scope of this study - to predict the fatigue crack rate (\%), flatness index (IRI), and permanent deformation depth. The data were used to evaluate the pavement life based on the analysis of permanent deformation, a standard related to plastic deformation. In this study, SMA mixture specifications and fiber grid reinforcement methods without input to pavement material properties predicted pavement life for plastic deformation by multiplying the ratio of WC-5 and PG 76-22 dynamic stability values, as shown in Table 7. In the case of the fluid-resistant asphalt mixture WC-5 PG $76-22$, the fatigue crack, flatness index, and permanent deformation satisfied the design criteria for 10 years. Therefore, under the same conditions, the analysis was conducted for 20 years to predict the exact pavement life of $15 \mathrm{~mm}$.

Table 7. Pavement performance analysis result.

\begin{tabular}{|c|c|c|c|c|c|}
\hline \multirow{2}{*}{ Section } & \multirow{2}{*}{ Service Period (year) } & \multicolumn{2}{|c|}{ Permanent Deformation (mm) } & \multirow{2}{*}{ Pavement Life (year) } & \multirow{2}{*}{ Note } \\
\hline & & Design & Analysis Result & & \\
\hline WC-5 PG64-22 & 20 & 15 & 19.1 & 3.67 & \\
\hline WC-5 PG76-22 & 20 & 15 & 16.7 & 11.67 & Basal Value \\
\hline SMA PG64-22 & 20 & 15 & - & 13.74 & \\
\hline SMA PG76-22 & 20 & 15 & - & 12.93 & \\
\hline $\begin{array}{l}\text { SMA PG76-22 } \\
+ \text { Grid }\end{array}$ & 20 & 15 & - & 17.24 & \\
\hline
\end{tabular}

Except for the fluid-resistant mixture WC-5 PG 64-22, in the ten years of the public service period, the standards showed a permanent deformation value of less than $15 \mathrm{~mm}$, which is the design commonality standard. Thus, the commonality of pavement could be secured against plastic deformation.

\subsection{Analysis of Economic Feasibility}

Economic feasibility was analyzed, including initial construction and maintenance costs through the lifetime of the pavement. Table 8 represents road pavement cost analysis results separated by SMA mixtures grade.

The analysis period includes the initial construction and maintenance costs during the public period based on the width of one lane and extension of $1 \mathrm{~km}$. The analysis period is 35 years, which is converted to Net Present Value (NPV); however, the user cost is excluded from the initial construction cost. The maintenance cost was derived by calculating the number of times during the analysis period (35 years), considering the pavement life. The same values as the initial construction method were applied, as shown in Equation (1).

$$
\begin{aligned}
N P V(\text { Net Present Value }) & \\
& =\text { Initial Investment } \\
& +\sum_{t}(\text { maintenance Cosst }+U \operatorname{ser} \operatorname{Cos} t)\left[\frac{1}{(1+i)^{t}}\right]
\end{aligned}
$$

here $i=$ discount rate $(3.5 \%)$, 
$t=$ year of analysis (35-year)

Table 8. Road pavement cost analysis results.

\begin{tabular}{|c|c|c|c|c|c|}
\hline \multicolumn{2}{|c|}{ Section } & \multirow{2}{*}{$\begin{array}{c}\text { Cost (\$) } \\
1947\end{array}$} & \multirow{2}{*}{$\begin{array}{l}\text { Unit Price } \\
0.56 \$ / \mathrm{m}^{2}\end{array}$} & \multirow{3}{*}{$\begin{array}{c}\text { Basis for Calculation } \\
3.5 \mathrm{~m} \times 1000 \mathrm{~m} \times 0.56 \$ / \mathrm{m}^{2} \\
3.5 \mathrm{~m} \times 1000 \mathrm{~m} \times 0.05 \mathrm{~m} \times \\
2.4 \text { ton } \times 51.73 \$ / \text { ton }\end{array}$} & \multirow{2}{*}{$\begin{array}{c}\text { Note } \\
\text { Standard market price }\end{array}$} \\
\hline & Construction cost & & & & \\
\hline WC-5 PG64-22 & Material cost & 21,725 & $51.73 \$ /$ ton & & Manufacturing cost \\
\hline \multirow{2}{*}{ WC-5 PG76-22 } & Construction cost & 1947 & $0.56 \$ / \mathrm{m}^{2}$ & $3.5 \mathrm{~m} \times 1000 \mathrm{~m} \times 0.56 \$ / \mathrm{m}^{2}$ & Standard market price \\
\hline & Material cost & 24,225 & $57.68 \$ /$ ton & $\begin{array}{c}3.5 \mathrm{~m} \times 1000 \mathrm{~m} \times 0.05 \mathrm{~m} \times \\
2.4 \text { ton } \times 57.68 \$ / \text { ton }\end{array}$ & Manufacturing cost \\
\hline \multirow{2}{*}{ SMA PG64-22 } & Construction cost & 1947 & $0.56 \$ / \mathrm{m}^{2}$ & $3.5 \mathrm{~m} \times 1000 \mathrm{~m} \times 0.56 \$ / \mathrm{m}^{2}$ & Standard market price \\
\hline & Material cost & 31,325 & $74.58 \$ /$ ton & $\begin{array}{c}3.5 \mathrm{~m} \times 1000 \mathrm{~m} \times 0.05 \mathrm{~m} \times \\
2.4 \text { ton } \times 74.58 \$ / \text { ton }\end{array}$ & Manufacturing cost \\
\hline \multirow{2}{*}{ SMA PG76-22 } & Construction cost & 1947 & $0.56 \$ / \mathrm{m}^{2}$ & $3.5 \mathrm{~m} \times 1000 \mathrm{~m} \times 0.56 \$ / \mathrm{m}^{2}$ & Standard market price \\
\hline & Material cost & 34,402 & 81.91 \$/ton & $\begin{array}{c}3.5 \mathrm{~m} \times 1000 \mathrm{~m} \times 0.05 \mathrm{~m} \times \\
2.4 \text { ton } \times 81.91 \$ / \text { ton }\end{array}$ & Manufacturing cost \\
\hline \multirow[t]{2}{*}{$\begin{array}{l}\text { SMA PG76-22 } \\
\text { + Grid }\end{array}$} & Construction cost & 1947 & $0.56 \$ / \mathrm{m}^{2}$ & $\begin{array}{l}3.5 \mathrm{~m} \times 1000 \mathrm{~m} \times 0.56 \$ / \mathrm{m}^{2} \\
3.5 \mathrm{~m} \times 1000 \mathrm{~m} \times 0.05 \mathrm{~m} \times\end{array}$ & Standard market price \\
\hline & Material cost & 60,260 & $81.91 \$ /$ ton $+7.39 \$ / \mathrm{m}^{2}$ & $\begin{array}{c}2.4 \text { ton } \times 81.91 \$ / \text { ton }+3500 \\
\mathrm{~m} 2 \times 7.39 \$ / \mathrm{m}^{2}\end{array}$ & Manufacturing cost \\
\hline Cutting $(5 \mathrm{~cm})$ & Construction cost & 18,105 & $5.17 \$ / \mathrm{m}^{2}$ & $3.5 \mathrm{~m} \times 1000 \mathrm{~m} \times 5.17 \$ / \mathrm{m}^{2}$ & Maintenance cost \\
\hline
\end{tabular}

The NPV analysis result of the road pavement by the condition is shown in Figure 6. WC-5 PG 64-22 had the lowest dynamic stability value. In this case, the initial investment cost was the lowest, but the increase in the number of pavement maintenance due to the short pavement life resulted in the highest cost converted to NPV.

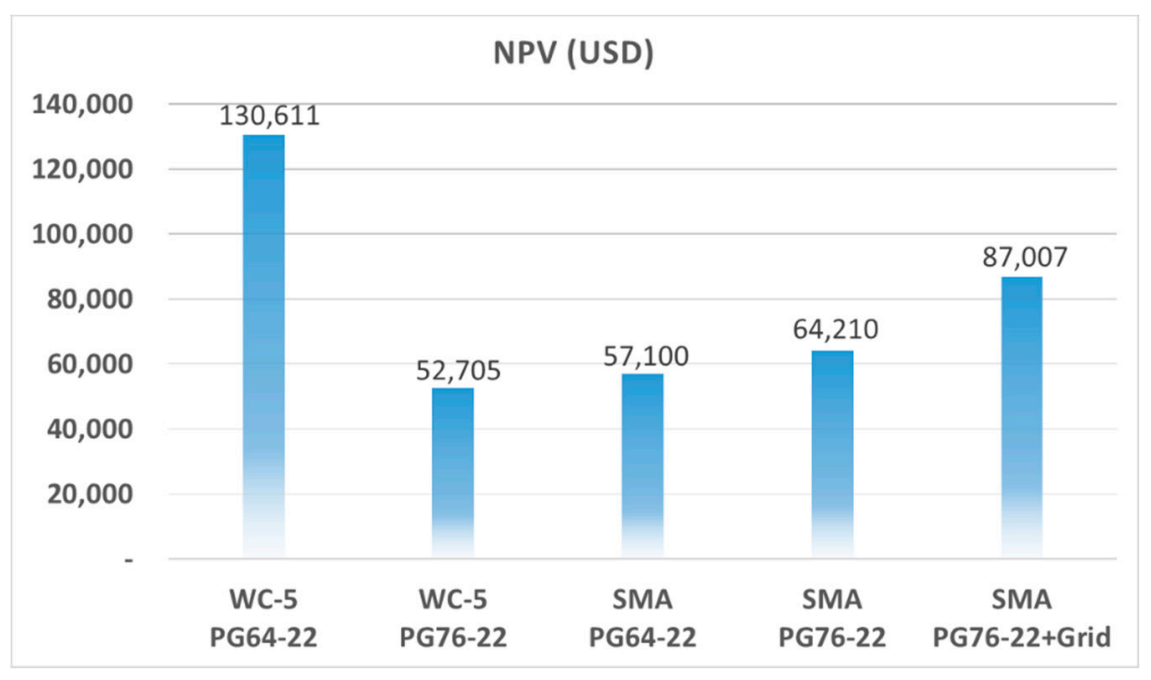

Figure 6. Road Pavement Economics Analysis Result.

Additionally, SMA PG 76-22+ with fiber grid reinforcement presented the highest dynamic stability value. However, it did not have economic feasibility because the initial cost of the material was 1.7 to 2.8 times higher than other structures, and the entire life cycle cost was the second highest. Although the dynamic stability of WC-5 PG 76-22 was the second-lowest of the five structures because of the relatively long pavement life and low construction costs, it was determined the most economically feasible.

\subsection{Application of Plastic Deformation Reduction Measures}

To find a method for decreasing plastic deformation, five asphalt mixtures were put through a wheel tracking test. The results were analyzed alongside factors that impact the commonality and economic feasibility of the five structures. Despite lacking economic feasibility, SMA PG 76-22+ with fiber grid reinforcements could ensure high resistance 
against plastic deformation. Therefore, in metropolitan intersection areas, applying limited amounts of the material in certain sections from the intersection vehicle stop line ensures high resistance. In other sections, WC-5 PG 76-22 is the recommended material, as it could maintain $68 \%$ of the dynamic stability and result in $42 \%$ of cost savings. Additionally, when using asphalt binders with SMA methods, maximizing the interlocking features of aggregates and improving the volume and quality of aggregates did not have much effect in reducing plastic deformation. Therefore, when considering commonality, using PG 64-22 normal straight binders should not be considered a hindrance.

\subsection{The Performance Test Standards for Asphalt Mixtures: Perspectives}

In this study, the tensile strength ratio and dynamic stability tests were used to analyze the performance of asphalt mixtures by specifications. However, it is crucial to integrate and modify specification standards and instruction contents to avoid omissions and inconsistencies in specifications and guidelines. For example, when applying PG 82-22 modified asphalt binders in SMA mixtures, the commonality grade was 3000 times per $\mathrm{mm}$. However, when the same modified asphalt binder PG 76-22 was applied, the dynamic stability of fluid-resistant asphalt was set to 2500 times per $\mathrm{mm}$. Additionally, there is no reference value for the Tensile Strength Ratio (TSR) in specifications manuals; the TSR was only applied as 0.85 in a 2017 asphalt concrete pavement construction guideline. However, even this value is unusually high with a 0.8 TSR of fluid-resistant mixtures with a dynamic stability value of 3000 times per $\mathrm{mm}$. This is also inconsistent with the drainage asphalt guideline in the same manual, which provides a TSR higher than 0.85 and a dynamic stability value higher than 3000 ties per $\mathrm{mm}$. To address these problems, it is advisable to apply the same TSA and dynamic stability to the fluid-resistant asphalt, drainage asphalt, and the SMA mixtures when using the same class of aggregates and asphalt binders.

\section{Conclusions}

\subsection{Study Summary and Significance}

The overall result of the study on the reduction of plastic deformation in the intersection of heavy traffic in urban areas is presented here. First, $20 \mathrm{~mm}$ WC-5 mixtures should be applied, as its maximum aggregate size is advantageous in reducing plastic deformation among fluid-resistant asphalt mixture conditions. The satisfaction conditions should be fulfilled in the form of an S-Curve avoiding the restriction of the Superpave to the underside of it. First-grade aggregates with less than $10 \%$ elongated particles should be used. Second, in WC-5 mixtures, PG 64-22 normal straight asphalt binders showed more than two times the resistance against plastic deformation. However, PG 76-22 modified asphalt binders are recommended as these have more commonality and economic feasibility. Third, in SMA mixtures where the interlocking feature of aggregates was maximized by increasing the use of coarse aggregates, better commonality and economic feasibility could be achieved by using the PG 64-22 normal straight asphalt binder instead of the PG 76-22 modified asphalt. Fourth, by applying fiber grid reinforcements to PG 76-22 SMA mixtures, a 25\% higher dynamic stability value than that of PG 64-22 SMA mixtures was observed. However, because of the high construction costs, the economic feasibility was insufficient. Fifth, the prediction of pavement life by the performance analysis resulted in the analysis of net present value economics under the mixing conditions of each fluid-resistant mixture and clade-mastic mixture. The results also showed a WC-5 with a relatively long pavement life and low construction costs during the 35-year analysis period. Sixth, the researchers recommended the application of the fiber grid-reinforced PG76-22 SMA mixture, with the best resistance to plastic deformation for certain sections up to 20-30 m from the vehicle stop line. Finally, when applying tensile strength ratio and dynamic stability as the standard for asphalt mixture performance tests, the specifications and instructions differ from each other. This calls for their reorganization.

Through this study, more objective and efficient ways of reducing plastic deformation were analyzed. In prior studies, theoretical interpretations and experimental results were 
derived primarily from indoor combination design conditions. Contrarily, through objective experimental results and performance analysis, field engineers may economically and realistically apply this study to construction.

\subsection{Suggestions for Reducing Plastic Deformation}

The experimental studies in this research objectively analyzed several ways of reducing plastic deformation. However, the interest and willingness of the participants to implement the systematic guideline are more important. Although excellent solutions are provided as guidelines to overcome plastic deformation, the effects of these solutions cannot be guaranteed unless the efforts and practices of participating engineers are applied to the design, construction, and supervision.

Based on the results of this study, the researchers recommend the following improvements in technical skills throughout design, construction, and supervision. First, more realistic traffic conditions and diverse pavement material variables should be considered for applying for road pavement design programs as a design method. Plastic deformation is closely related to the properties of aggregates. An accurate public performance should be analyzed by supplementing the class of aggregates and parameter values of the materials for the pavement of the clade mastic. Next, the most economical method should be selected. When presenting this in the design budget, it is crucial to reflect the most appropriate measures for the entire life cycle from a macro perspective, such as aggregate grades, binder grades, compositional design conditions, etc. Second, quality control in the production and construction process of asphalt mixtures is a key to impact pavement life significantly.

However, most construction sites still rely on hands-on experience to manage their work. The ordering agencies and construction management facilities supervising these actions lack an overall understanding of pavement, thereby leading to a passive stance on reducing plastic deformation. To solve this problem, more facilities specializing in pavement should be founded to supervise the quality control of pavement. Moreover, it is necessary to operate a systematic and regular management program involving those in charge of ordering, construction project management, construction work, and production companies. Third, as a long-term improvement measure, it is necessary to secure appropriate business periods and project costs suitable for the construction technology of the world's top 10 economies. Thus far, the management system evaluates the lowest price first. Consequently, all construction project costs in Korea are not reflected in the appropriate project price. The construction period also lacks proper reflection of the five-day workweek or legal holidays. Furthermore, this excessive push for construction is leading to poor quality. Finally, institutional improvements based on related consultations will certainly decrease the social costs from the faulty pavement, such as plastic deformation and cracks. In future studies, cracks should also be analyzed since the cost for fixing cracks would be another big part of the financial burden to transportation agencies, decreasing the fatigue life of the pavement.

Author Contributions: Conceptualization, S.S.; methodology, S.S.; validation, S.S. and C.Y.; formal analysis, S.S.; investigation, S.S.; data curation, S.S.; writing_-original draft preparation, S.S.; writingreview and editing, C.Y.; visualization, C.Y.; supervision, C.Y.; project administration, C.Y.; funding acquisition, C.Y. All authors have read and agreed to the published version of the manuscript.

Funding: This study was supported by the National Research Foundation of Korea (NRF) grant funded by the Korea government (MSIT) (grant no. 2019R1C1C1001997).

Institutional Review Board Statement: Not applicable.

Informed Consent Statement: Not applicable.

Data Availability Statement: Data is contained within the article.

Conflicts of Interest: The authors declare no conflict of interest. 


\section{References}

1. Chae, H.Y. Study on subsurface collapse of road surface and cavity search in urban area. Tunn. Undergr. Space 2017, 27, 387-392.

2. Prusov, D. Aspects of the influence assessment of the new construction during the reconstruction of urban territory areas in the dense building conditions. Proc. Natl. Aviat. Univ. 2013, 56, 91-97. [CrossRef]

3. Moreno, F.; Sol, M.; Martín, J.; Pérez, M.; Rubio, M.C. The effect of crumb rubber modifier on the resistance of asphalt mixes to plastic deformation. Mater. Des. 2013, 47, 274-280. [CrossRef]

4. Xu, G.; Chen, Z.; Li, X.; Lu, G.; Dong, D.; Liu, Z. Simple prediction model for plastic deformation of graded crushed stone base for flexible pavement. Mater. Struct. 2020, 53, 1-16. [CrossRef]

5. Li, D.; Selig, E.T. Cumulative plastic deformation for fine-grained subgrade soils. J. Geotech. Eng. 1996, 122, 1006-1013. [CrossRef]

6. Chai, J.C.; Miura, N. Traffic-load-induced permanent deformation of road on soft subsoil. J. Geotech. Geoenviron. Eng. 2002, 128, 907-916. [CrossRef]

7. Kashani, H.F.; Hyslip, J.P.; Ho, C.L. Laboratory evaluation of railroad ballast behavior under heavy axle load and high traffic conditions. Transp. Geotech. 2017, 11, 69-81. [CrossRef]

8. Causes and Influencing Factors of Plastic Deformation. Available online: http:/ / db.koreascholar.com/article.aspx?code=248886 (accessed on 2 March 2021).

9. Ling, M.; Luo, X.; Gu, F.; Lytton, R.L. Time-temperature-aging-depth shift functions for dynamic modulus master curves of asphalt mixtures. Constr. Build. Mater. 2017, 157, 943-951. [CrossRef]

10. Al-Azri, N.A.; Jung, S.H.; Lunsford, K.M.; Ferry, A.; Bullin, J.A.; Davison, R.R.; Glover, C.J. Binder oxidative aging in Texas pavements: Hardening rates, hardening susceptibilities, and impact of pavement depth. Transp. Res. Rec. 2006, 1962, 12-20. [CrossRef]

11. Chiu, C.T.; Lu, L.C. A laboratory study on stone matrix asphalt using ground tire rubber. Constr. Build. Mater. 2007, 21, 1027-1033. [CrossRef]

12. Madhkhan, M.; Azizkhani, R.; Harchegani, M.T. Effects of pozzolans together with steel and polypropylene fibers on mechanical properties of RCC pavements. Constr. Build. Mater. 2012, 26, 102-112. [CrossRef]

13. Choi, J.S.; Lee, K.H.; Kwon, S.A.; Jeong, J.H. An analytical study to reduce plastic deformation in intersection pavements. Int. J. Highw. Eng. 2012, 14, 29-36.

14. Xu, Q.; Solaimanian, M. Modelling linear viscoelastic properties of asphalt concrete by the Huet-Sayegh model. Int. J. Pavement Eng. 2009, 10, 401-422. [CrossRef]

15. Kim, Y.R.; Little, D.N. Linear viscoelastic analysis of asphalt mastics. J. Mater. Civ. Eng. 2004, 16, 122-132. [CrossRef]

16. Ko, S.B. An Experimental Study on the Rutting Factors in Asphalt Concrete Pavement. Ph.D. Thesis, Chung Ang University, Seoul, Korea, 2001.

17. Ock, C.K.; Kim, D.H.; Lee, K.H. Minimizing the rutting in asphalt pavement surface with dense grade mixtures. Korea Soc. Civ. Eng. 1999, 4, 181-184.

18. Kim, K.W.; Cho, H.W.; Do, Y.S. Evaluation of rut and fatigue resistance of selected polymer-modified asphalt concretes. Korea Soc. Civ. Eng. 1998, 18, 635-643.

19. Yeo, H.D.; Kim, G.D.; Kwon, S.A.; Jeong, J.H. Evaluation of early age performance of geogrid-reinforced asphalt pavements. Int. J. Highw. Eng. 2010, 12, 53-60.

20. Cho, S.D.; Lee, D.Y. Performance evaluation of asphalt pavement reinforced with glass fiber sheet type of geosynthetics. J. Korean Geosynth. Soc. 2011, 10, 1-8.

21. Road Pavement Structure Design Guide. Available online: https://www.codil.or.kr/detailAnwGuide.do?nserialno=1074 (accessed on 2 March 2021). 